\title{
ERRO ESCOLAR: DA PUNIÇÃO À CONSTRUÇÃO, UM LONGO CAMINHO A PERCORRER
}

Dáugima Maria Santos Queiroz*

"A vida não é rigorosa. Ela propicia erros $e$ acertos. Os erros podem ser transformados em acertos quando com eles se aprende. Não existe a segurança do acerto eterno."

(Içami Tiba)

Repetidas vezes, temos visto, sempre acompanhando a temática da avaliação da aprendizagem, a questão do papel e função do erro no seio escolar, sendo colocada numa perspectiva de construção do conhecimento.

No campo da Psicologia Genética, o "erro" se apresenta, apenas, com uma função indicativa, diagnóstica. Jean Piaget nos leva a pensar sobre a estrutura que o erro aponta e não destaca o erro em si, mesmo como fonte de dificuldades.

*Graduada em Pedagogia pela FUCMT, pós-graduada (lato sensu) em Didática do Ensino Superior, professora de Didática e Prática de Ensino na UCDB e cursa o programa de Mestrado em Educação na UCDB. 
O erro, no desenvolvimento da criança e do adolescente, funciona, isto sim, como

"a tomada de consciência do professor sobre os esquemas assimilativos e estruturas que estão sendo utilizados por seus alunos na resolução de problemas. Em suma, a indicação e definição de seus objetivos de trabalho pedagógico." (Lima, 1994:86).

No entanto, em nossa prática pedagógica, estamos aceitando realmente o erro dos nossos alunos como fator de construção de conhecimento, ou ainda estamos apenas "teorizando"?

Por que esta prática é dificil de ser concretizada? Por que o erro ainda não é aceito por muitos de nós? Ou pior, por que o erro é algo abominável, que leva à punição e, tantas vezes, à auto-punição?

Luckesi em seu artigo "Prática Escolar: do erro como fonte de castigo ao erro como fonte de virtude", nos coloca que

"A visão culposa de erro na prática escolar, tem conduzido ao uso permanente do castigo como forma de correção e direção da aprendizagem, tomando a avaliação como suporte da decisão" (Luckesi, 1990).

E continua:

"Hoje essas fomas de castigar (as fisicas) são raras, porém o castigo não desapareceu da escola. Ele se manifesta de outras maneiras, que não 
atingem imediatamente o corpo fisico do aluno, mas sua personalidade..." (Luckesi, 1990).

E sabemos que não é raro, em nossas instituições escolares, as crianças e os adolescentes sofrerem da "síndrome do medo", diante de ameaças como provas, supensão do recreio, realização de tarefas extras e muitas outras atividades punitivas.

Essa correção enérgica do erro, desempenhada pelo educador com tanta precisão, tendo um papel social de controle eficaz, leva os alunos à introjeção da angústia, da indignidade e da culpa.

Os alunos, na grande maioria das nossas escolas, são "podados" em função dos erros que cometem, e a supervalorização da resposta certa está sempre presente em sala de aula, sendo, freqüentemente, premiados, com elogios, os alunos acertadores.

"Atualmente o erro é tão indesejável que se tornou comum o uso de "corretivos" (líquido corretor) por parte dos alunos, numa tentativa de eliminar qualquer vestígio do erro" (Vasconcelos, 1992).

Se os erros dos alunos são entendidos como hipóteses de construção do conhecimento, e estes (os erros) devem fazer parte da aprendizagem, temos, então, um excelente material de análise do educando, pois revela como ele está pensando, possibilitando ajudá-lo a reorientar a construção do conhecimento.

"Foi a partir do que a escola e os demais profissionais de educação consideram como 
"dificuldade", "déficit", "erro" da criança que melhor consegui captar a sua construção própria, em relação ao objeto de conhecimento" (Costa, 1993:69.).

Este depoimento faz parte da dissertação de mestrado de Dóris Anita Freire Costa, sob o título: "Fracasso Escolar: diferença ou deficiência". Ao procurar sistematizar a questão da especificidade de conhecimento de crianças de classes populares, mostrando que o que era considerado "déficit" não passava de "diferenças", a autora defrontou-se com uma dificuldade metodológica: como verificar, na prática, a especificidade de conhecimento dessas crianças? Como aproximar-se mais desse sujeito, como ouvi-lo melhor, a fim de captar o seu conhecimento?

As observações das aulas no Setor de Reeducação Pedagógica, ligado à Escola Estadual Yolanda Martins Silva, situada na Grande Belo Horizonte, não ofereceram suficientes elementos essenciais para a sistematização da questão. A pesquisadora chegou à conclusão de que a forma de melhor solucionar o problema seria partir dos "erros" da criança, o que permitiria aproximar-se mais do seu pensamento.

Como as crianças das aulas de Reeducação haviam sido submetidas ao Teste Metropolitano de Prontidão, nas chamadas "avaliações psicopedagógicas", cujos "erros" eram apontados, a autora tomou as respostas consideradas erradas e, para compreender o "porquê" dos erros e "como" estes eram produzidos, decidiu submeter novamente as questões a essas crianças.

O Teste Metropolitano de Prontidão - Forma R 
(TMP), publicado nos Estados Unidos Por Hildret e Griffiths (1949), traduzido e adaptado para nossa realidade por Poppovic (1964), é considerado básico para determinar a prontidão do aluno para a alfabetização.

$\mathrm{Na}$ reaplicação do referido teste, as respostas das crianças foram minuciosamente exploradas, isto é, as crianças eram levadas a dizer por que haviam dado aquelas respostas e a mostrar como as haviam elaborado.

As respostas e atividades das crianças ofereceram um material bastante rico, cuja análise permitiu à autora verificar, de certa forma, a originalidade e especificidade de pensamento de cada criança.

As respostas dadas pelas crianças e consideradas "erradas" foram, pois, extremamente lógicas. Extremamente lógicas e, ainda, expressão transparente de sua experiência concreta de vida, no saber que elas trazem de sua prática cotidiana e que é rejeitada pela escola (Costa, 1993:81).

Numa perspectiva transformadora, o que se propõe é que a ação avalista e o erro, em particular, sejam trabalhados como uma privilegiada oportunidade de interação entre o educando e o educador e entre os próprios educandos, de modo a superarem suas hipóteses em direção a outras mais complexas e abrangentes. $\mathrm{O}$ professor e o aluno passam, ambos, a serem sujeitos do processo. O aprendiz sendo respeitado em suas etapas de desenvolvimento e o professor devendo ser um porto-seguro, demonstrando confiança na possibilidade daquele estar aprendendo sempre.

Estas ações, entretanto, são tarefas dificeis, que exigem discernimento por parte do docente, para distinguirem 
os erros construtivos, aqueles que evidenciam progressos na estrutura mental, daqueles erros que não sinalizam crescimento intelectual e/ou cognitivo da criança.

Um primeiro passo, para entendimento e distinção desta questão, seria um aprofundamento nos estudos referentes aos conceitos de estrutura e procedimentos (Inhelder e Piaget, 1979). Os erros de ordem estrutural são erros que todas as crianças, em um certo momento de seu desenvolvimento, cometem. São erros que definem um nível de relação com os objetos de conhecimento. Existem, no entanto, os erros que ocorrem quando à criança é oferecida uma gama de procedimentos possíveis de serem empregados para resolução da situação-problema, e esta terá que escolher alguns desses possíveis caminhos que melhor resolvam a tarefa proposta. Ora, nesse momento, a criança pode acertar como também pode errar. Segundo Macedo (1994) "O importante é sabermos a serviço do que está a correção e qual seu sentido -estrutural ou funcional-para a criança".

Os professores das séries iniciais do $1^{\circ} \mathrm{Grau}$, como também os pais que acompanham seus filhos principiantes nas atividades escolares, sabem que a criança erra bastante na execução de seu trabalho.

Davis C. e Esposito Y. L. (1990) encontraram três alternativas que podem dar significado aos erros cometidos pela criança:

1) Erros de procedimentos - cometidos no emprego ou aprimoramento dos conhecimentos já construídos. A criança possui a estrutura de pensamento necessária para a 
realização da terefa, mas ao sistematizar, selecionou procedimentos inadequados, por distração ou falta de treinamento. Quando a criança comete erro de ortografia e esta já possui a estrutura alfabética, não podemos dizer que são "erros construtivos" e, sim, erros de sistematização do código escrito, pois a criança já elaborou a constução da língua escrita. Neste caso, a avalição depende da observação constante do professor em relação à evolução da produção da lógica do sistema alfabético de representação.

2) Erros construtivos - estes sinalizam a formação de novas estruturas, a gênese de novas construções cognitivas. A criança errou, porque a estrutura de pensamento, que possui, não é suficiente para realizar a tarefa, ou seja, existem lacunas em sua estrutura de pensamento que dificultam a assimilação dos dados disponíveis.

Como não possui um entendimento claro do que lhe cabe realizar, nem elementos necessários para optar por um determinado curso de ação, a criança age por tentativa e erro, fazendo correções em função dos êxitos e dos fracassos da ação que realizou. Neste momento, o conjunto de elementos ou "teorias" que compõem a estrutura cognitva da criança, não estão mantendo em si uma relação de "equilíbrio", porque a situação que lhe é colocada é geradora de perturbações em sua forma de pensar. A fonte dos erros reside nas contradições entre as hipóteses construídas pelo próprio sujeito, que implicam tanto em uma dificuldade para compreender a questão quanto para selecionar uma estratégia de ação. E aqui entra a importante ação do docente, de fazer uso dos desequilíbrios apresentados por seus alunos de forma a lhes propiciar condições para construir novas 
estruturas cognitivas e chegar a novos estados de equilíbrios.

O professor deve estar atento para oferecer contrapropostas que permitam à criança continuar avançando em suas hipóteses, tornando-as mais abrangentes e superiores às precedentes.

3) Erros por limites na estrutura do pensamentopor não possuir a estrutura necessária à solução da tarefa, a criança fica impossibilitada de compreender o que lhe é solicitado. O aluno não é capaz de assimilar o problema, enquanto perturbado, seja porque seu sistema cognitivo não se encontre suficientemente desenvolvido, seja porque a tarefa não se lhe apresente como perturbadora. Se o elemento apresentado não provoca nenhum efeito sobre a criança é porque o referido elemento não representa problema para ela. $\mathrm{O}$ que fazer, então, para que as crianças percebam as contradições, desequilibrem-se e busquem superá-las, ultrapassando sua antiga forma de pensar? $\mathrm{O}$ professor, criando um ambiente de sala de aula propício para o diálogo, consegue ouvir da criança a justificativa e a demonstração das razões pelas quais adotou um dado padrão de ação. Portanto, é função do educador levar a criança a refletir sobre os "porquês" e os "comos" da ação (Macedo, 1987), num clima de cooperação e nunca sob coação. Desta forma, as hipóteses individuais são discutidas de modo que a troca de pensamento possibilite a apreensão de perturbações, acionando o processo de equilibração.

Aprofundando nos estudos acerca do erro, tomamos conhecimento da importante e delicada tarefa que envolve a prática docente. Isto porque o professor deve distinguir a natureza dos erros de aprendizagem cometidos pela criança, 
e fornecer-lhes condições para superá-los. É fundamental fazer com o que o aluno, paulatinamente, tome consciência e perceba o seu próprio erro.

Os estudos sobre aprendizagem operatória (Inhelder, Sinclair \& Bonet, 1977) nos auxiliam com a apresentação de situações criadas, nas quais o erro pode ser um dado observável para o aluno, sendo esta questão fundamental no campo pedagógico, pois o professor orientando os seus alunos de maneira distinta, a depender da natureza dos erros cometidos, estes serão superados.

Nesse mesmo sentido, não podemos deixar de acrescentar as grandes contribuições de Emilia Ferreiro e Ana Teberosky (1995) por criarem situações de pesquisa, em que certos aspectos da construção da escrita na criança podem ser observados por ela.

As autoras supracitadas afirmam que, em termos práticos, o ponto de partida de toda a aprendizagem é o próprio sujeito (definido em função de seus esquemas assimiladores à disposição) e não o conteúdo a ser abordado. As propriedades desse objeto serão, ou não, observáveis para um sujeito, e não as suas capacidades sensoriais. Trata-se, portanto, de detectar quais são os momentos cruciais, nos quais o sujeito é sensível às perturbações, para ajudá-lo a avançar no sentido de uma nova reestruturação.

Hoffmann (1994) nos leva a refletir sobre o significado da prática secular de correção de tarefas e provas, realizadas pelos professores, que, numa prática avaliativa tradicional, são ações voltadas para verificar respostas certas 
e erradas, com base nessa verificação, convoca-nos:

"A analisar teoricamente as várias manifestações dos alunos em situação de aprendizagem, (verbais ou escritas, outras produções), para acompanhar as hipóteses que vêm formulando a respeito de determinados assuntos, em diferentes áreas de conhecimento, de forma a exercer uma ação educativa que lhes favoreça a descoberta de melhores soluções ou a reformulações de hipóteses preliminarmente formuladas. Acompanhamento que visa o acesso gradativo do aluno a um saber competente na escola, e portanto sua promoção a outras séries e graus de ensino" (Hoffmann, 1993).

Trata-se, já vimos, de uma tarefa árdua. Mesmo perseguindo claramente esses princípios teóricos, provavelmente o professor terá dificuldade em dizer para o aluno, para os pais, que uma tarefa, um trabalho represente uma etapa preliminar de aprendizagem e não pode ser, simplesmente, conceituada em certo/errado.

Em sala de aula, o professor deve propiciar uma metodologia que leve o aluno a uma participação efetiva (problematização, debate, dramatização, pesquisa, experimentação, trabalho em grupos etc.), se entender que o sujeito só adquire conhecimento quando, num processo ativo, reconstrói o objeto de conhecimento. Caso contrário, o aluno se desinteressa pela aula, as dúvidas se acumulam e o professor não tem elementos para fazer uma avaliação contínua da aprendizagem. As dúvidas, os "erros" revelam 
ao professor o percurso que o aluno está fazendo na construção do seu conhecimento.

A participação do aluno no processo ensinoaprendizagem na sua totalidade e na prática da avaliação, em particular, é um contigente fundamental para que ele tenha melhores condições de aprender, efetivamente, pois tomando consciência do seu erro, este poderá ser superado, imediatamente.

O trabalho do professor comprometido passa também pela superação do seu isolamento, ou seja, as atividades docentes exigem participações solidárias. A equipe escolar necessita conquistar espaço constante e reflexão coletiva sobre a sua prática, a fim de lutar contra a fragmentação e as relações autoritárias na escola, e desta forma mudar o que tem que ser mudado.

As escolas, que vêm buscando transformações no processo ensino-aprendizagem e na prática de avaliação, precisam envolver as famílias nas discussões de sua proposta pedagógica e nas eventuais mudanças na prática em relação à avaliação. Tal atividade visa a favorecer o seu próprio trabalho com os alunos, à medida que possibilite que se conheçam seus contextos de vida, de costumes e valores culturais de suas famílias, e as diferenças ou semelhanças existentes entre elas e em relação à proposta.

O conhecimento, o relacionamento franco e a participação das famílias dos alunos na escola são componentes fundamentais numa proposta pedagógica, principalmente, em se tratando de um compromissso firmado com uma educação democrática. Isto é possível entendendo a relação escola-família na sua dimensão social, 
respeitando os modos de agir e pensar dos pais, valorizando seus costumes e tradições, mas, simultaneamente, explicitando metas, atitudes e prioridades educacionais.

O intercâmbio escola-sociedade, visando ao melhor conhecimento do aluno, colabora, naturalmente, para uma maior qualidade no trabalho pedagógico, e este avanço acontecerá à medida que os professores e as escolas compreenderem que, partindo justamente do erro, contribuirão para a construção de conhecimentos de seus alunos.

\section{REFERÊNCIAS BIBLIOGRÁFICAS}

COSTA, Dóris Anita Freire. Fracasso escolar: diferença ou deficiência. Porto Alegre : Kuarup, 1993.

DAVIS, Cláudia \& ESPOSITO, Yara Lúcia. Papel e função do erro na avaliação escolar. Caderno de Pesquisa (74), agosto de 1990.

FERREIRO, Emília e TEBEROSKY, Ana. Psicogênese da lingua escrita. Tradução de Diana Myriam Lichtenstein. Porto Alegre : Artes Médicas, 1985.

HILDRETH, Gertrude H. e GRIFFITHS, Nelle L. Teste metropolitano de prontidão forma $R$ : Manual de aplicação. São Paulo: Vetor, 1986.

HOFFMANN, Jussara Maria Lerch. Avaliação mediadora: uma prática em construção da pré-escola à universidade. Porto Alegre : Educação e Realidade, 1993. 
INHELDER, B. et alli. Aprendizagem e estruturas do conhecimento. Trad. Maria Aparecida Rodrigues Cintra e Maria Aparecida Rodrigues Cintra e Maria Yolanda Rodrigues Cintra. São Paulo: Saraiva, 1977.

INHELDER, e PIAGET J. Procedimentos e estruturas. Archives de Psychologie. Genebra (47), 161-76, 1979.

IDÉIAS, Revista. Avaliação do rendimento escolar n 22. São Paulo, 1994.

LIMA, Adriana de Oliveira. Avaliação do rendimento escolar: julgamento ou construção? Petrópolis, RJ : Vozes, 1994.

LUCKESI, Cipriano Carlos. Prática escolar: do erro como fonte de castigo ao erro como fonte de virtude. Revista de Tecnologia Educacional, 101, 1991.

MACEDO, Lino de. Ensaios construtivistas. São Paulo : Casa do Psicólogo, 1994.

VASCONCELLOS, Celso dos S. Avaliação: concepção dialética libertadora. São Paulo: Libertad, 1992. 